\title{
Cytophotometric mapping of neuronal changes in senile dementia
}

\author{
D. M. A. MANN, ${ }^{1}$ P. O. YATES, AND C. M. BARTON
}

From the Department of Pathology, The Medical School, Manchester

SUMMARY Results of a cytophotometric study have shown a widespread reduction in cytoplasmic RNA of nerve cells. It appears, therefore, that although certain aspects of the symptomatology of senile dementia may be accounted for by lesions in particular anatomical sites, the main part of the neurological disturbance is related to more broadly based changes in nerve cell metabolism affecting much, if not all, of the CNS.

Mental deterioration occurring in old age, usually termed senile dementia, is one of the most common, yet most poorly understood of neurological conditions. A great number of the early and, indeed, the recent studies (Dayan, 1970; Tomlinson et al., 1970; Colon, 1973; Gibson et al., 1976) have attempted to evaluate its pathogenesis and severity in terms of the most obvious neuropathological findings-namely, senile plaques and neurofibrillary tangles-but as yet the relevance of these features to the underlying mechanism remains uncertain.

Other studies have taken a more biochemical viewpoint. Reports by Gottfries and co-workers (1969, 1974), and Fisher (1972), have indicated a generalised disturbance of monoamine metabolism in the brains of patients suffering from senile dementia. Other reports have implied that accumulation within neurones of lipoprotein pigments may play a significant role in the disease process. Gedye et al. (1972) noted that treatment of some patients suffering from organic dementia with meclofenoxate (Lucidril) improved intellectual function; meclofenoxate has been shown (Nandy, 1968; Spoerri and Glees, 1974) to cause a reduction in lipofuscin in cerebral nerve cells in rodents.

Elsewhere, a number of observations have suggested that metallic intoxications may play a part in dementia. Crapper et al. (1973) showed that aluminium levels in brains of patients with Alzheimer's disease were about four times higher than those of normal controls. Moreover, subarachnoid injection of aluminium salts in cats induced a

\footnotetext{
${ }^{1}$ Address for correspondence and reprint requests: Dr D. M. A. Mann, Department of Pathology, Stopford Building, University of Manchester, Oxford Road, Manchester M13 9PT, England.

Accepted 16 November 1976
}

progressive encephalopathy characterised by neurofibrillary degeneration of nerve cells (Klatzo et al., 1965) which showed many of the clinical features of senile dementia (Crapper et al., 1973). Nikaido et al. (1972) measured increased amounts of silicon in senile plaques and tangle-bearing neurones.

Finally, genetic studies of recent years (Larsson et al., 1963) suggest that dementia is genetically determined by a dominant autosomal gene with late phenotypical penetrance.

The diversity of these findings emphasises the present lack of knowledge surrounding the pathogenesis of both Alzheimer's disease and senile dementia.

A technique has been developed in this department which we believe allows both major and minor disease in nerve cell groups to be detected. This method involves measurement of a number of nuclear and cytoplasmic features, including nerve cell cytoplasmic RNA content which is an indicator of the capacity of such cells to form the proteins appropriate for neurophysiological function. We report here our findings in the aged, and in cases clinically assessed as suffering from senile dementia.

\section{Patients and methods}

Nervous tissue was obtained at necropsy from 10 patients suffering from senile dementia, and from 15 control subjects of a similar age group who were free from overt neurological illness at death.

Paraffin sections of selected blocks of tissue were cut at $16 \mu \mathrm{m}$ and stained for cell RNA (Shea, 1970).

Measurements of nerve cell RNA content were made, as detailed elsewhere (Mann and Yates, 1974; Mann et al., 1976), on various cell types including 
Purkinje cells, cells of the olivary and dentate nuclei, cells of the lateral ventral nucleus of thalamus, cells of the locus caeruleus and substantia nigra, Betz cells of the precentral gyrus, cells of the motor nucleus of III, V, VI, VII, VIII and XII cranial nerves, and pyramidal cells of all areas of the hippocampus. A minimum of 100 cells of each type was measured in every case, and the mean RNA content calculated. From these mean values of RNA, an overall mean and standard deviation were derived for the group of demented patients as a whole and similarly for the controls.

\section{Results}

Results of overall mean cell RNA content derived for each neurone group from 10 demented patients and 15 normal control subjects of similar age range are shown in the Table. The difference in overall mean cell RNA content between the demented and the control groups exceeds the $5 \%$ level of significance in all groups of neurones studied and the $0.1 \%$ level in most cases. These differences are expressed in the Table as mean percentage losses of cell RNA from neurones of the demented group.

As argued earlier (Mann and Yates, 1974), it is appropriate to use the amount of cell RNA as an

Table Mean cell RNA content $( \pm S D)$ for various nerve cell types as measured in 10 patients suffering from senile dementia and 15 normal controls of a similar age group. Also shown is level of significance of the difference between dements and controls, and the mean percentage loss of RNA from the dement group of cases

\begin{tabular}{|c|c|c|c|c|c|}
\hline \multirow{2}{*}{\multicolumn{2}{|c|}{ Cell type }} & \multicolumn{2}{|c|}{ Mean cell RNA content } & \multirow[t]{2}{*}{$P$} & \multirow{2}{*}{$\begin{array}{l}\text { Mean loss } \\
(\%) \\
\text { RNA }\end{array}$} \\
\hline & & Dements & Controls & & \\
\hline \multicolumn{2}{|c|}{$\begin{array}{l}\text { III } \\
\text { V } \\
\text { VI } \\
\text { VII } \\
\text { VIII } \\
\text { XII } \\
\text { Betz cell } \\
\text { Purkinje cell } \\
\text { Dentate } \\
\text { Thalamus } \\
\text { Olives } \\
\text { Locus caeruleus } \\
\text { Subs. nigra }\end{array}$} & $\begin{array}{r}31.9 \pm 5.5 \\
32.1 \pm 3.7 \\
26.5 \pm 3.1 \\
28.2 \pm 3.6 \\
22.2 \pm 3.2 \\
29.2 \pm 4.2 \\
41.7 \pm 3.0 \\
22.7 \pm 3.3 \\
16.3 \pm 8.1 \\
22.5 \pm 3.3 \\
8.2 \pm 4.2 \\
23.8 \pm 3.6 \\
24.1 \pm 3.5\end{array}$ & $\begin{array}{l}34.6 \pm 3.8 \\
39.0 \pm 4.8 \\
29.4 \pm 3.8 \\
42.0 \pm 7.6 \\
26.0 \pm 3.5 \\
32.9 \pm 4.3 \\
53.7 \pm 3.3 \\
31.6 \pm 4.0 \\
23.5 \pm 4.0 \\
25.8 \pm 3.1 \\
11.2 \pm 2.9 \\
26.2 \pm 2.6 \\
27.6 \pm 3.8\end{array}$ & $\begin{array}{l}<0.05 \\
<0.001 \\
<0.05 \\
<0.001 \\
<0.01 \\
<0.01 \\
<0.001 \\
<0.001 \\
<0.001 \\
<0.01 \\
<0.001 \\
<0.01 \\
<0.01\end{array}$ & $\begin{array}{r}7.8 \\
17.9 \\
9.8 \\
32.8 \\
14.5 \\
11.3 \\
22.3 \\
28.2 \\
30.8 \\
13.0 \\
26.2 \\
9.2 \\
12.7\end{array}$ \\
\hline \multirow{6}{*}{ 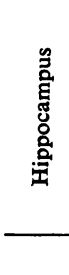 } & $\mathbf{h}_{1}$ & $11.5 \pm 0.4$ & $13.8 \pm 0.5$ & $<0.001$ & 17.0 \\
\hline & $\mathbf{h}_{\mathbf{2}}$ & $10.1 \pm 7.2$ & $20.6 \pm 0.5$ & $<0.001$ & 51.2 \\
\hline & $\mathbf{h}_{3}$ & $13.7 \pm 6.1$ & $20.5 \pm 0.6$ & $<0.001$ & 33.4 \\
\hline & $\mathbf{h}_{4}$ & $11.6 \pm 5.6$ & $20.8 \pm 0.4$ & $<0.001$ & 44.5 \\
\hline & $\mathbf{h}_{5}$ & $14.5 \pm 1.9$ & $21.6 \pm 0.4$ & $<0.001$ & 32.6 \\
\hline & Age (yr) & $83.8 \pm 3.5$ & $84.3 \pm 3.9$ & $>0.05$ & - \\
\hline
\end{tabular}

index of the level of potential for function present in that cell. As shown in the Table, there are losses of cell RNA for every neuronal type measured, ranging from $7-51 \%$, implying a corresponding reduction in their overall capacity for function.

\section{Discussion}

Changes in RNA content of nerve cells have been related to various pathological conditions. Firstly, there is transynaptic degeneration in which loss of function in a group of neurones follows destruction of those cells which make synaptic connection with it, or with which it makes such connection. This leads to reduction in cytoplasmic RNA (chromatolysis).

Secondly, there are situations of abnormal hyperactivity, such as prolonged electrical stimulation (Watson, 1968), and physical exhaustion which have been shown to result in increased production of RNA. Thus the basic level of RNA present in nerve cells at any one time may be varied in extreme conditions, according to the metabolic demands imposed by the state of functional activity.

A progressive decline in RNA in nerve cells has, $\dot{\omega}$ been shown (Mann and Yates, 1974; Mann et al, i 1976) to be a feature of aging, and this is linked to the accumulation of lipoprotein pigments in the celi 윽 body.

The widespread loss of RNA from nerve cells which we have shown to be a feature of senile demene tia, therefore, suggests an overall decline in the leves of activity of nerve cells throughout the whole of the nervous system. To what might this general decline in activity be attributed?

Gedye et al. (1972) noted that treatment with meclofenoxate of some patients suffering from senile dementia improved intellectual function, and moreover Nandy (1968) demonstrated that this compound could bring about a reduction in lipofuscin in cerebral nerve cells of experimental animals. These studies infer that lipoprotein pigments may play some part in the disease process. It may, therefore, be argued that in senile dementia, the measured RNA losses could come about because of increased levels of pigmentation. However, it has been shown (Mann and Sinclair, 1977) that there is no significant difference in mean pigment levels between a demented and a non-demented control group of patients, of similar age range, for cells of the inferior olivary nucleus and pyramidal cells of the hippocampus. Both groups of patients show pigment accumulation appropriate to their age. Therefore, despite the observations of Nandy (1968), and Spoerri and Glees (1974), that meclofenoxate beneficially reduces lipofuscin levels in nerve cells, it seems unlikely that pigment removal, per se, has any bearing on the im- 
provement in intellectual function reported by Gedye et al. (1972) after treatment with the drug.

Other authors have reported disturbances in catecholamine metabolism in brains of patients suffering from senile dementia. Gottfries et al. $(1969,1974)$ measured reduced CSF levels of homovanillic acid (HVA), and 5 hydroxyindoleacetic acid (HIAA), the major breakdown products of dopamine and 5hydroxytryptamine (5HT) respectively. Furthermore, Fisher (1972) measured reduced levels of HVA but no decrease in 4-hydroxy-3-methoxy mandelic acid (VMA), the major noradrenaline metabolite, in the urine of demented patients. In our study, neurones of the substantia nigra were shown to have lost, on average, some $13 \%$ cell RNA. Thus, the findings of reduced levels of HVA in CSF and urine, indicative of a reduction in dopamine metabolism, taken in conjunction with that of RNA loss, suggest a decreased activity, though not necessarily a dysfunction of neurones of the substantia nigra. Similarly, the widespread reduction in HIAA, indicative of a general disturbance in 5HT metabolism, can be related to the general loss of RNA seen in cells of the cerebral cortex.

Noradrenaline bearing neurones are restricted, within the CNS, to cells of the locus caeruleus (Olson and Fuxe, 1971; Ungerstedt, 1971; Kobayashi et al., 1974), and thus constitute only a tiny proportion of the total number of noradrenaline cells in the body. It is hardly to be expected that changes in noradrenaline metabolism in the locus caeruleus would be reflected in changes in urinary VMA. Cells of the locus caeruleus have been shown to give rise to pathways innervating the hippocampus and all cortical areas (Ungerstedt, 1971; Kobayashi et al., 1974), cerebellum (Olson and Fuxe, 1971; Ungerstedt, 1971; Kobayashi et al., 1974), and certain nuclei of the thalamus and hypothalamus (Kobayashi et al., 1974). Through these pathways the locus caeruleus is thought to influence the level of activity of these higher cortical areas (Olson and Fuxe, 1971), and thus indirectly, the whole of the CNS. Lesions in the locus caeruleus, resulting in reduced catecholamine output, would, therefore, be expected to cause a decline in neurological activity throughout the brain, possibly reflected in the widespread loss of RNA in neurones of demented patients that we have observed.

Our studies show that cells of the locus caeruleus have lost, on average, only some $9 \%$ RNA, and such a figure does not appear to suggest a substantial reduction in noradrenaline metabolism in these neurones; however, it cannot be ruled out altogether.

We have shown that greatest losses of RNA occur in pyramidal cells of areas $h_{2}-h_{5}$ of Ammon's horn in the hippocampus (Table). Tomlinson and Kitchener
(1972) found that, in senile dementia, these cells were more severely affected by granulovacuolar degeneration than in a control group of non-demented persons of similar age range, and that in most cases, this change was restricted to this cell type. It is likely, therefore, that the higher loss of RNA we have measured in these cells is related to the presence and severity of this type of degeneration.

The relationship of these lesions in the hippocampus to dementia is not clear. It is known that patients suffering from senile dementia show severe memory defects, especially for recent events and for the assimilation of fresh information (Kral, 1972; Miller, 1973), while long-term recall is relatively unaffected. Furthermore, non-demented patients who have displayed serious memory disturbances typical of senile dementia have, at necropsy, shown severe loss of pyramidal cells of the hippocampus (Victor et al., 1961). Thus, it is possible that these lesions in the hippocampus may account for the memory defects associated with senile dementia, but the main body of neurological disturbances are probably related to more broadly based changes in nerve cell function.

Mehraein et al. (1975), using a modified Golgi technique, reported a decrease in both the number of dendrites and the extent of dendritic arborisation, not only in cells of the hippocampus and cingulate gyrus, but also in Purkinje cells of the cerebellum, for patients with both Alzheimer's disease and senile dementia. These latter changes in the cerebellum are particularly notable since Purkinje cells have been thought to be largely unaffected by these diseases. These authors were, therefore, of the opinion that Alzheimer's disease and senile dementia affect nerve cells throughout the CNS, the involvement consisting essentially of a reduction of dendritic number and extent.

Our own findings of widespread reductions in cytoplasmic RNA in senile dementia indicate a general decline in metabolic levels which may have followed, or indeed produced, a reduction in dendritic arborisation in affected nerve cells.

We thank the Wellcome Trust who generously supported this work.

\section{References}

Colon, E. J. (1973). The cerebral cortex in presenile dementia-a quantitative analysis. Acta Neuropathologica (Berlin), 23, 281-290.

Crapper, D. R., Dalton, A. J., and Krishnan, S. S. (1973). Brain aluminium distribution in Alzheimer's disease and experimental neurofibrillary degeneration. Science, 180, 511-513.

Dayan, A. D. (1970). Quantitative histological studies on 
the human aged brain. II. Senile plaques and neurofibrillary tangles in senile dementia. Acta Neuropathologica (Berlin), 16, 95-102.

Fisher, R.H.(1972). The urinary excretion of HVA and 4hydroxy-3-methoxymandellic acid in the elderly demented. Gerontological Clinics, 14, 172-175.

Gedye, J. L., Exton-Smith, A. N., and J. Wedgwood (1972). A method for measuring mental performance in the elderly and its use in a pilot clinical trial of meclofenoxate in organic dementia. Age and Ageing, 1, 74-80.

Gibson, P. H., Stones, M., and Tomlinson, B. E. (1976). Senile changes in the human neocortex and hippocampus compared by the use of electron and light microscopes. Journal of the Neurological Sciences, 27, 389-405.

Gottfries, C. G., Gottfries, I., and Roos, B. E. (1969). Homovanillic acid-5 hydroxyindoleacetic acid in CSF of patients with senile dementia, presenile dementia and Parkinsonism. Journal of Neurochemistry, 16, 1341-1345.

Gottfries, C. G., Kjallquist, A., Ponten, U., Roos, B. E., and Sundbarg, G. (1974). CSF, pH and monoamine and glucolytic metabolites in Alzheimer's disease. British Journal of Psychiatry, 124, 280-287.

Klatzo, I., Wisniewski, H., and Streicher, E. (1965). Experimental production of neurofibrillary degeneration. I. Light microscope observations. Journal of Neuropathology and Experimental Neurology, 24, 187-199.

Kobayashi, R. M., Palkovits, M., Kopin, I. J., and Jacobowitz, D. M. (1974). Biochemical mapping of noradrenergic nerves arising from the rat locus caeruleus. Brain Research, 77, 269-279.

Kral, V. A. (1972). Senile dementia and normal ageing. Canadian Psychiatric Association Journal, 17 (Suppl. 2), 25-30.

Larsson, T., Sjoergen, T., and Jacobson, G. (1963). Senile dementia: a clinical, sociomedical and genetic study. Acta Psychiatrica Scandinavica, 39 (Suppl. 167), 10-259.

Mann, D. M. A. and Sinclair, K. G. A. (1977). Investigations into the action of meclofenoxate in senile dementia. Age and Ageing. (In Press).

Mann, D. M. A. and Yates, P. O. (1974). Lipoprotein pigments-their relationship to ageing in the human nervous system. I-The lipofuscin content of nerve cells. Brain, 97, 481-488.

Mann, D. M. A., Yates, P. O., and Barton, C. M. (1976). Melanin and RNA in cells of the human substantia nigra. Journal of Neuropathology and Experimental Neurology. (In Press.)

Mehraein, P., Yamada, M., and Tarnowska-Dziduszko, E. (1975). Quantitative study on dendrites and dendritic spines in Alzheimer's disease and senile dementia. Advances in Neurology, 12, 453-458.

Miller, E. (1973). Short and long term memory in patients with presenile dementia (Alzheimer's disease). Psychological Medicine, 3, 221-224.

Nandy, K. (1968). Further studies on the effect of centrophenoxine on the lipofuscin pigment in neurones of senile guinea pigs. Journal of Gerontology, 23, 82-92.

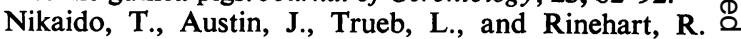
(1972). Studies in ageing brain. II Microchemical के analyses of the nervous system in Alzheimer patients. Archives of Neurology (Chicago), 27, 549-554.

Olson, L. and Fuxe, K. (1971). On the projections from the locus caeruleus noradrenaline neurones: the cerebellar innervation. Brain Research, 28, 165-171.

Shea, J. R. (1970). A method for the in situ cytophotometric estimation of absolute amount of ribonucleic acid using Azure B. Journal of Histochemistry and Cytochemistry, 18, 143-152.

Spoerri, P. and Glees, P. (1974). The mode of lipofuscio removal from hypothalamic neurones. Experiment os Gerontology, 10, 225-228.

Tomlinson, B. E., Blessed, G., and Roth, M. (1970)Observations on the brains of demented old people Journal of the Neurological Sciences, 11, 205-242.

Tomlinson, B. E. and Kitchener, D. (1972). Granulo vacuolar degeneration of hippocampal pyramide cells. Journal of Pathology, 106, 165-185.

Ungerstedt, U. (1971). Stereotaxic mapping of the monoamine pathways of the rat brain. Acta Physiologica Scandinavica (Suppl. 367), 1-48.

Victor, M., Angevine, J. B., Mancall, E. L., and Fisher, C. M. (1961). Memory loss with lesions of the hippocampal formation. Archives of Neurology (Chicago), 5, 244-263.

Watson, W. E. (1968). Observations on the nucleolar and total cell body nucleic acid of injured nerve cells. Journal of Physiology (London), 196, 655-676. 